\title{
Avaliação dos métodos de detecção das alterações do gene e proteína P53 nas neoplasias linfóides
}

Claudete E. Klumb

Geraldo B. Cavalcanti Júnior ${ }^{2}$
A proteína p53 desempenha um papel central na resposta celular que inclui a parada do ciclo celular permitindo o reparo do dano no DNA, ou indução da morte celular. A perda da função dessa proteína pode levar à proliferação celular desordenada, aumento da sobrevida da célula e resistência às drogas quimioterápicas. 0 gene supressor de tumorp53 é alterado em diversas neoplasias, entre as quais se incluem as neoplasias hematológicas. Estas alterações são, em sua maioria, mutações que levam à perda da capacidade da proteína p53 de regular a transcrição de diversos genes envolvidos em importantes processos da célula. Ao contrário da proteína selvagem, cuja degradação ocorre rapidamente depois da síntese, as formas mutadas da proteína têm a meia vida aumentada e se acumulam dentro da célula possibilitando a detecção por imunohistoquímica. As mutações do gen£53 ocorrem com uma freqüência em torno de $12.5 \%$ nas neoplasias hematológicas, no entanto, em alguns tipos de linfomas não Hodgkin (LNH), particularmente, nos linfomas de Burkitt, freqüências superiores têm sido observadas. A maior parte das mutações do gene p53 são mutações do tipo missense e ocasionam perda da função e estabilização da proteína. Entretanto, alta expressão da proteína selvagem também tem sido detectada por imunohistoquímica, o que indica uma discrepância entre mutações do gene e detecção da proteína.

O objetivo deste trabalho é realizar uma revisão dos métodos usados para identificar as alterações do gene e da proteína p53 com ênfase nas neoplasias linfóides, visando determinar o seu envolvimento nessas neoplasias. Rev.bras.hematol.hemoter.,2002, 24(2):111-125

Palavras-chaves: Gene supressor de tumop53, proteína p53, neoplasias linfóides

\section{Introdução}

Oncogenes e genes supressores de tumor têm sido associados a diferentes tipos de neoplasias, sendo o gene p53 o que com maior freqüência apresenta alterações (1). Este gene localiza-se no braço curto do cromossomo 17 (17p13.1) e codifica uma fosfoproteína nuclear de 53 kD que contém 393 aminoácidos. Esta proteína é capaz de se ligar a seqüências específicas do DNA sendo um fator de transcrição que controla de forma positiva ou negativa a expressão de diversos genes envolvidos

1 - Médica Hematologista. Lab. de Hematologia Celular e Molecular/ Serviço de Hematologia. Hospital do Câncer/ Instituto Nacional de Câncer. Doutoranda e estagiária do Lab. de Bioquímica e Biologia Molecular do Squistosoma Mansoni / Depto de Bioquímica Médica da UFRJ

2 - Professor Assistente da Disciplina de Imunologia Clínica do Depto de Análises Clínicas e Toxicológicas da UFRN. Doutorando e estagiário do Lab. de Hematologia Celular e Molecular/ Serviço de Hematologia Hospital do Câncer/ Instituto Nacional de Câncer

Correspondência para: Claudete E. Klumb

Praça da Cruz Vermelha, 23 - Centro. Rio de Janeiro/RJ - Brasil - CEP 20230-130

Telefone: (21) 506-6198 • E-mail: klumb@uol.com.br 
em várias vias celulares. Dentre as vias mais importantes se destacam a inibição da replicação do DNA, funcionando como uma molécula de check pointda progressão da célula no ciclo celular da fase $G 1$ para a fase $S$ e também da fase $G$ para fase M. Desta forma, é garantida a manutenção da integridade do genoma e o controle da proliferação celular (2, 3) [Figura 1]. Adicionalmente, a p53 também está envolvida na apoptose, embora uma via de apoptose independente da p53 tenha sido identificada (4).

Ao contrário dos outros genes supressores de tumor que são inativados por perda alélica, 0 gene p53 distingue-se pela alta freqüência de

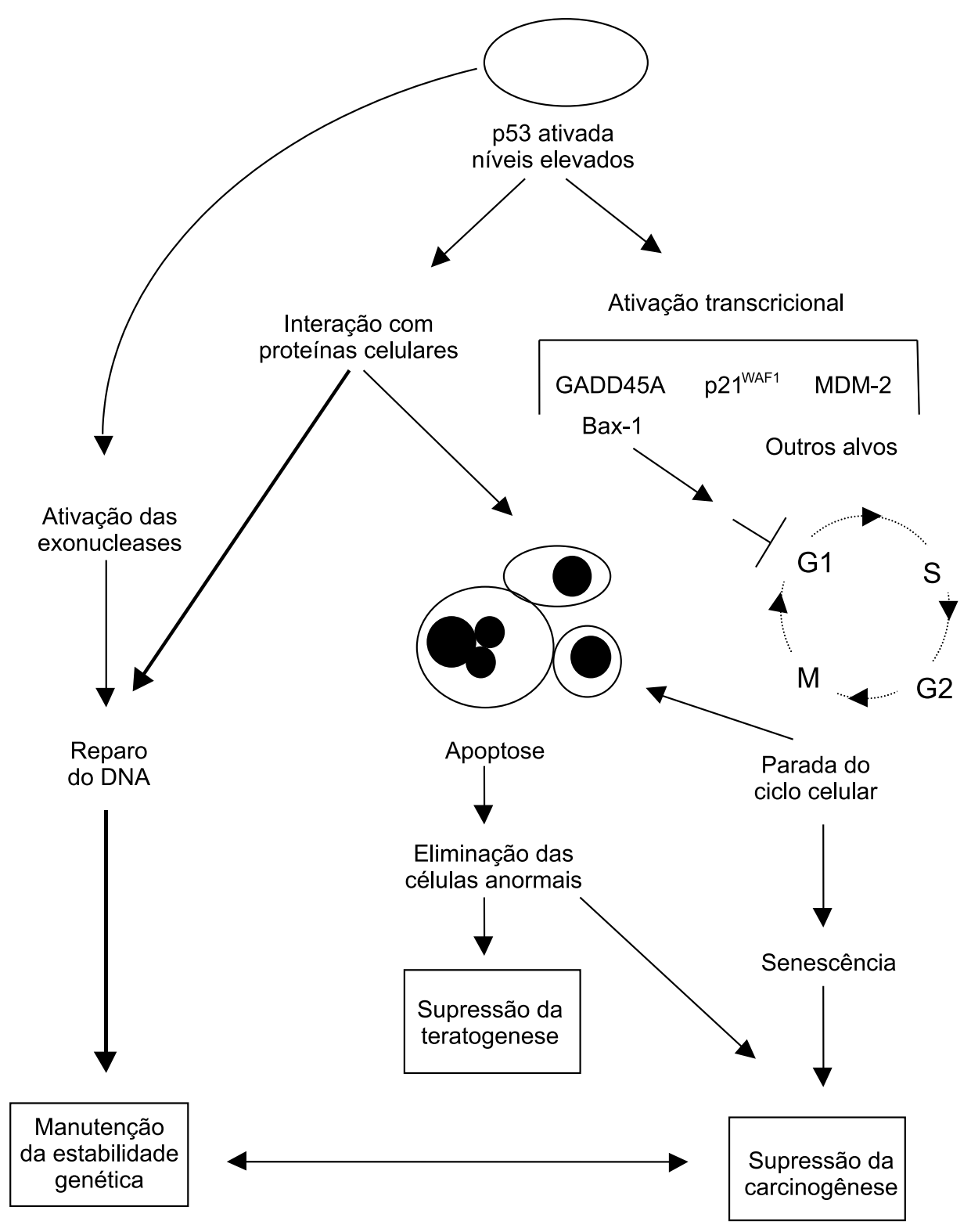

Figura 1. Heterogeneidade das vias de sinalização utilizadas pela proteína p53 em seu papel de "guardiã do genoma" 


\section{Mecanismos de inativação da p53}

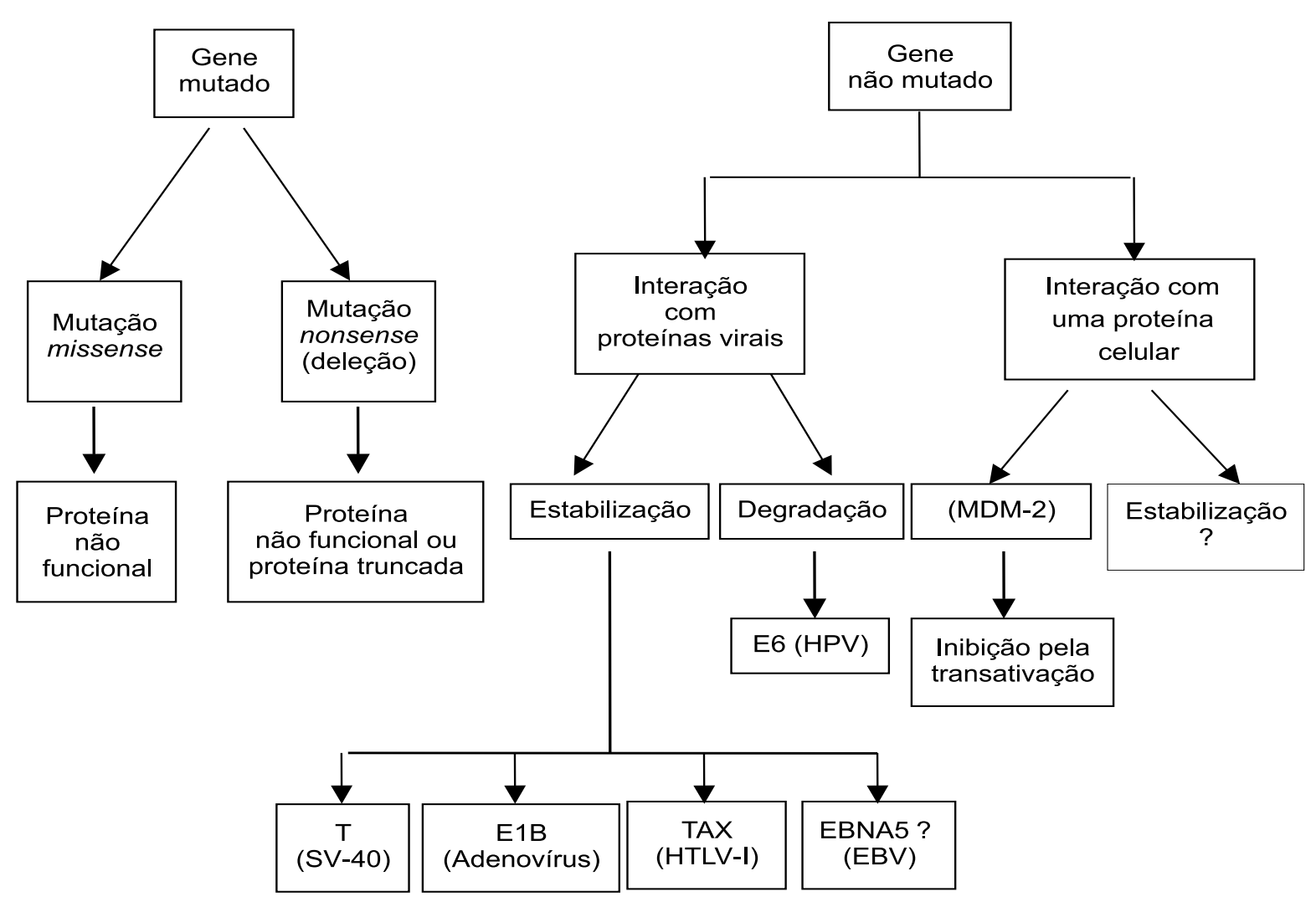

Figura 2. Diferentes mecanismos de inativação da proteína p53

mutações (5). A maioria dessas mutações é do tipo missense(troca de um nucleotídeo) e altera a função normal da proteína p53. Como resultado de mutações pontuais, a proteína tem sua meia vida aumentada e se acumula nas células tumorais (6). Também, embora em menor freqüência, as mutações podem ser do tipo nonsenseem virtude de deleções de porções do gene ou inserção de nucleotídeos. Este tipo de mutação pode levar a um stop codon (parada da leitura do RNA mensageiro) alterando a proteína e, em última análise, a ocorrência de uma proteína truncada [Figura 2]. Em síntese, a inativação da proteína p53 por mutação, perda, seqüestração ou ligação a outras proteínas como proteínas virais, pode levar ao aumento da proliferação, instabilidade genômica e perda de importantes mecanismos de controle do ciclo celular (7). Por outro lado, muitos quimioterápicos utilizados no tratamento das neoplasias promovem dano no DNA e conseqüente indução da apoptose via p53. A perda desta função pode resultar em resistência à apoptose e falha terapêutica (8).

É possível avaliar o impacto no meio científico da pesquisa do gene p53 e sua proteína, pelo número de pesquisas realizadas até 0 momento (9). A posição de guardiã da integridade do genoma (7) exerce uma incontestável sedução intelectual. Com efeito, depois de sua descoberta em 1979 (10), o gene p53 tem quebrado todas as teorias de definição de um gene tumoral: nem é um oncogene, nem é um antioncogene, um pouco dos dois, uma molécula incansável, segundo definição do pesquisador Pierre Hainaut (11). 
Nesta revisão é discutida a metodologia e a interpretação da presença de alterações do gene e proteína p53 nas neoplasias de origem linfóide. Para uma revisão mais detalhada da função da p53, o leitor deve consultar publicações recentes referentes a este tema $(9,12-14)$.

\section{M étodos de Análise do G ene p53}

A grande variação das alterações genéticas que incluem deleções, insersões, inversões e translocações permite a análise do DNA por vários métodos, no entanto, para avaliação de mutações envolvendo uma única base, ou grupos de bases, é necessária a comparação com a forma selvagem. 0 seqüenciamento direto de um gene, às vezes com vários kB de extensão, é dispendioso, vagaroso e impraticável quando o número de amostras é grande. A alternativa mais racional é a utilização de técnicas de screnning de mutações seguidas por seqüenciamento. Estas técnicas diferem em sensibilidade e são baseadas em diferenças no padrão de migração eletroforético ou comportamento cromatrográfico entre os mutantes e o DNA de referência (forma selvagem). Estes métodos incluem:

\section{Polimorfismo conformacional de fita sim- ples de DNA (SSCP: Strand Conformational Polimorphism)}

É o método mais utilizado na análise de mutações e envolve três etapas: i) amplificação por PCR da região do gene de interesse; ii) desnaturação do produto de PCR; iii) eletroforese da fita simples de DNA através de um gel com $\mathrm{pH}$ neutro. As moléculas de fita simples de DNA assumem uma complexa estrutura tridimensional como resultado do pareamento de suas bases. Fitas de igual tamanho, mas, com diferente seqüência, têm alterada a sua estrutura secundária e migram com um padrão eletroforético diferente. O SSCP permite a detecção de alteração na seqüência nucleotídica como a troca de um nucleotídeo $(15,16)$, no entanto, a eficiência de detecção é máxima quando a seqüência tem 150 a 200 pares de bases (17). Também, é importante analisar a migração em condições diferentes de temperatura e força iônica o que permite uma melhor resolução de alguns mutantes. O SSCP aumentou drasticamente a eficiência de identificação de mutações, porém, sua maior desvantagem é ser um método empírico. Até o momento, não existe um algoritmo capaz de prever o número de bandas de uma fita simples e, géis contendo muitas bandas podem ser difíceis de interpretar. Embora o SSCP possa detectar quase $100 \%$ das mutações, com freqüência, requer que uma variedade de condições seja testada e o padrão de separação de uma seqüência gênica não é reprodutível para outra $(18,19)$ [Figura 3a].

\section{PCR-Heteroduplex}

A técnica de PCR-heteroduplex baseia-se na diferença de mobilidade eletroforética entre a dupla fita homoduplex e a heteroduplex. A fita heteroduplex por possuir inserção ou deleção, não é totalmente complementar, havendo assim, a formação de alças que irão causar diferença de migração na eletroforese. Esta técnica consiste em desnaturar o produto do PCR de amostras contendo misturas de DNA com o gene normal e mutado. Em seguida, 0 pareamento das fitas simples ocorre à temperatura ambiente, sendo esse produto submetido a uma eletroforese em gel de poliacrilamida, com visualização da migração após coloração pelo nitrato de prata (18-20). Outras técnicas de screning de mutações como a eletroforese em gel de gradiente de desnaturação (DGGE), o PCR alelo específico e o teste da proteína truncada, são mais complexas e portanto pouco utilizadas (19).

\section{Seqüenciamento}

A confirmação e identificação de possível mutação detectada pela alteração de migração no SSCP ou heteroduplex é feita por seqüenciamento. Na última década, o método de término de cadeia descrito por Sanger (21, 22) sofreu significante refinamento com automatização, utilização de fluorocromos ligados aos dideoxy dNTPs e leitura em laser de argônio. O procedimento básico compreende desnaturação do DNA, anelamento do primer com a fita simples, extensão do primer pela 
Termosequenase em tubos com dNTPs não marcados e dideoxy dNTPs marcados com $\alpha^{32} \mathrm{P}$ ou fluorocromos. 0 produto desta reação é então separado em gel de alta resolução contendo poliacrilamida/uréia e a leitura da seqüência é obtida por exposição em filme de raio $\mathrm{X}$ ou com laser [Figura 3 b1, 3 b2].

\section{Hibridização in situ fluorescente (FISH)}

A análise do cariótipo de células tumorais é útil para investigação de alterações envolvendo o cromossomo 17, com maior freqüência as deleções do braço curto, localização do gene p53 (23). O FISH combina a especificidade e sensibilidade da hibridização de ácidos nucléicos com a informação citogenética. 0 princípio básico é a capacidade intrínseca da fita simples de DNA e RNA de anelar-se com a seqüência complementar e formar uma fita dupla. $\mathrm{O} \mathrm{FISH}$ tem a vantagem sobre as técnicas tradicionais de citogenética, pela possibilidade de estudar as células em interfase eliminando a necessidade de culturas de células (24). A deleção do locus 17 p53 pode ser estudada por FISH usando uma sonda (marcada com fluorocromo) para a região centromérica do cromossomo 17 e uma sonda específica para o locus do gene p53. Os sinais são visualizados simultaneamente e a ausência do sinal p53 em um dos cromossomas é indicativa de deleção (25).

\section{Métodos de D etecção da Proténa p53}

\section{Imunohistoquimica}

A proteína p53 selvagem é normalmente presente no núcleo das células e tem meia vida curta, não sendo detectada na maioria dos tecidos normais. Em contraste, a forma mutada tem meia vida prolongada sendo passível de detecção por técnicas imunológicas usando anticorpos monoclonais (AcMo) anti-p53 (25-27). 0 método da IH consiste na desparafinização dos cortes, exposição antigênica em panela de pressão ou forno de microondas, seguindo por marcação com
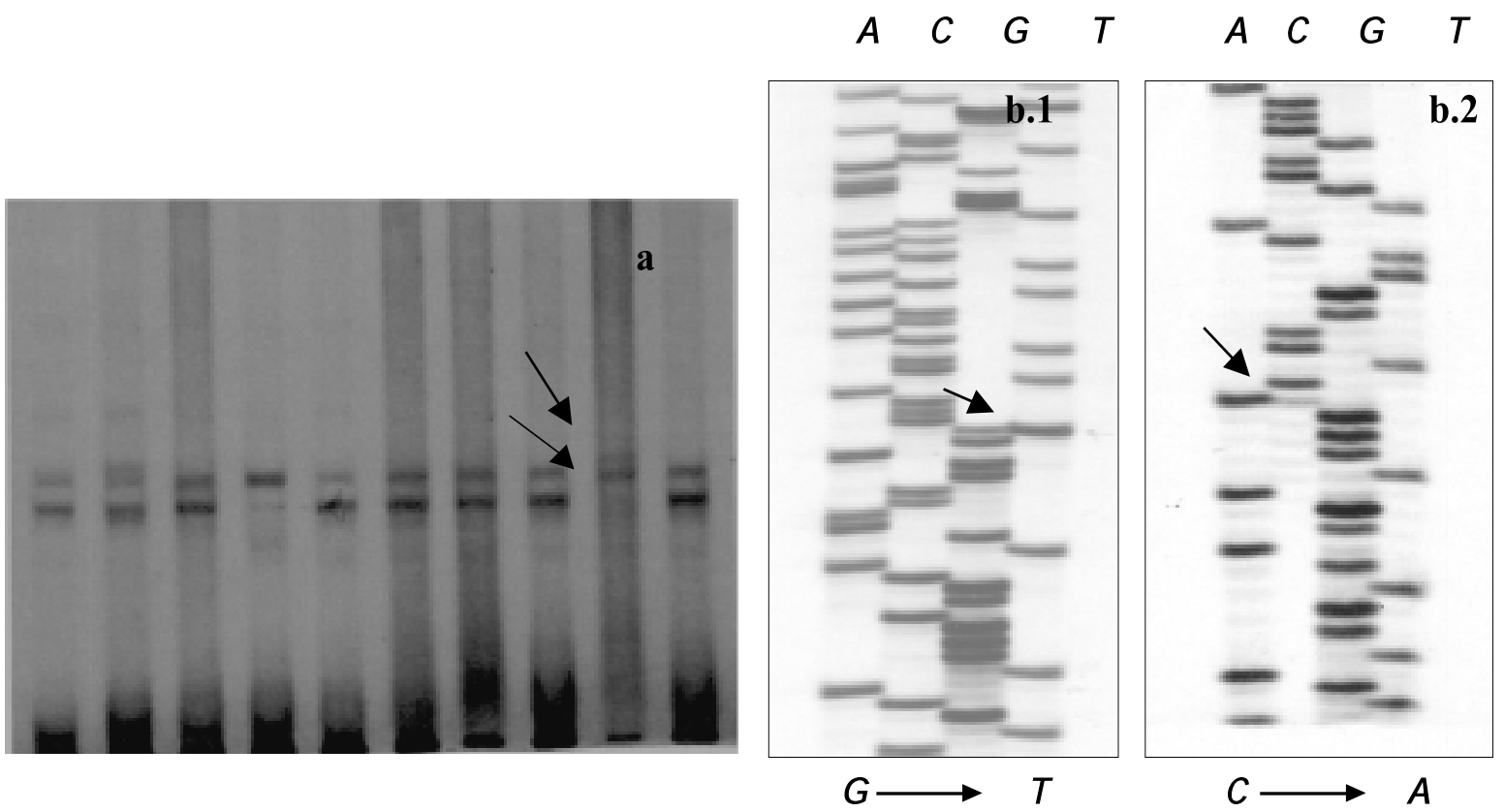

Figura 3. Mutação no codon 248 (Exon 7) do gene p53 em um caso de linfoma de Burkitt. a) PCR-SSCP mostrando alteração de migração indicativa de mutação (seta); $b$-1 e b-2) Seqüenciamento das fitas sense e antisense respectivamente, mostrando a troca do nucleotídeo guanina por timina e conseqüente substituição do aminoácido arginina por serina

(Resultados dos autores) 


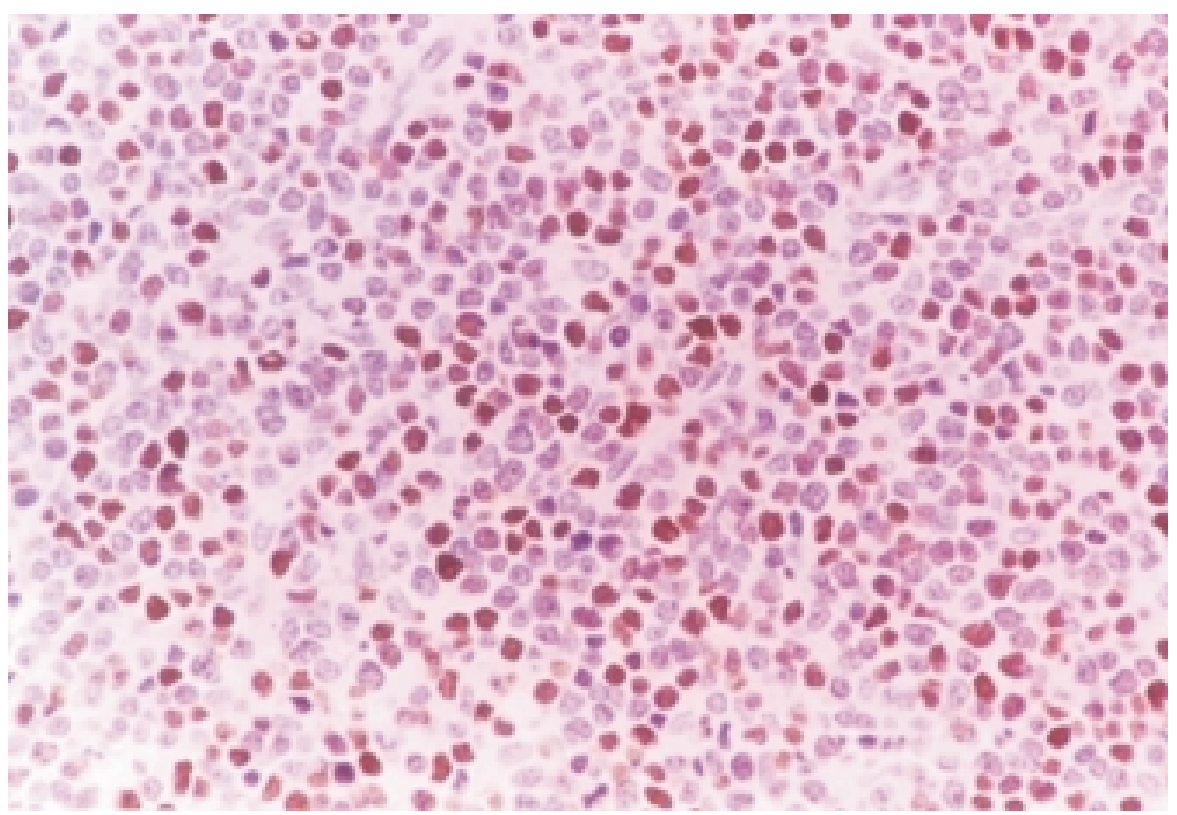

Figura 4. Estabilização da proteína p53 por mutação e deteç̧ão imunohistoquímica com Ac Mo antip53 D0-7 no mesmo paciente com Linfoma de Burkitt ilustrado na figura 2.

Cortesia: Dra Lidia Magalhães Cordeiro de Resende

o AcMo e revelação [Figura 4]. A IH tem suas limitações e a ausência de marcação não significa ausência de alteração da proteína (falso negativo). Inversamente, 0 acúmulo da proteína não é sinônimo de mutação $(25,28)$. A ausência de expressão da proteína pode ocorrer em virtude de condições adversas de fixação do tecido diminuindo a sensibilidade da técnica. Mutações do tipo nonsense podem impedir a deteç̧ão da proteína. Por outro lado, a proteína pode ser detectada em tecidos normais em situações de indução fisiológica frente a alterações acidentais do genoma. Uma forte positividade na maioria das células tumorais indica uma disfunção da proteína, podendo corresponder à mutação ou estabilização por outro mecanismo $(28,29)$.

Entre as técnicas existentes para investigação da inativação da p53, a IH é mais freqüentemente utilizada. Entretanto, os resultados podem variar pelo uso de diferentes anticorpos monoclonais, modos de incubação, variações nos métodos de recuperação antigênica, subjetividade dos escores e ausência de um valor cutoff uniforme para definir os casos positivos (29).

\section{Imunocitoquímica (ICQ)}

A ICQ é um método de avaliação da expressão que permite utilizar células em suspensão ou inprint de tecidos tumorais e tem como vantagem a correlação dos resultados com o estudo citomorfológico e a identificação precisa da localização da proteína na célula. A técnica utiliza células previamente fixadas em lâmina, que são submetidas à permeabilização e incubadas com AcMo anti-p53 (30). A presença da proteína é revelada por meio da adição do anticorpo secundário com especificidade contra a imunoglobulina de camundongo, que está associado a um substrato revelador. Este substrato pode ser uma peroxidase ou uma fosfatase alcalina [Figura 5a].

Um fator limitante na detecção da p53 por ICQ é a rápida degradação da proteína, sendo necessária a preservação do material em baixa temperatura $\left(-70{ }^{\circ} \mathrm{C}\right)(30,31)$.

\section{Citometria de fluxo}

A citometria de fluxo (CF) pode ser utilizada como método de estudo da expressão da p53 (32, 33). Esta metodologia distingue-se por ser prática e permitir avaliar a expressão de mais de uma proteína 
envolvida no controle do ciclo celular e na apoptose, tais como MDM-2, p21, Bcl-2, Bax e outras. Como todas são proteínas presentes no citoplasma ou no núcleo, é necessária a permeabialização prévia (34), o que possibilitará o acesso dos anticorpos conjugados a diferentes fluorocromos, cuja emissão de luz, em diferentes comprimentos de onda, será lida e quantificada em cada célula [Figura 5b, 5c].

Este méto do tem vantagem em relação a ICQ porque enquanto na ICQ a positividade é baseada em um número baixo de eventos (geralmente são contadas 200 células), na CF são considerados 10.000 eventos, valor este mais representativo da amostra estudada.

\section{Western Blot}

0 western blotpara detecção da p53, embora seja um método de alta especificidade e sensibilidade, é pouco utilizado. Este método além de demorado, tem muitas etapas que dificultam sua aplicação principalmente em um número grande de amostras (35).

\section{D iscussão}

\section{p53 e neoplasias linfóides}

A freqüência de mutações do gene $p 53$ em neoplasias de origem linfóide é de $12.5 \%$ (36). No entanto, em certos tipos histológicos como a leucemia linfoma $T$ do adulto e o linfoma de Burkitt, têm sido observadas freqüências de até $40 \%(37,38)$.

A revisão dos estudos do gene p53 e sua proteína nas neoplasias linfóides, em primeira instância fornecem resultados que podem sugerir conclusões precipitadas. Em sua grande maioria, 0 desenho do estudo e/ou os métodos de análise estatística não permitem uma avaliação adequada. Nieder et al. (39), ao revisar toda a literatura sobre 0 valor preditivo e prognóstico de alterações do gene p53 nos linfomas não Hodgkin, podem selecionar sete estudos e, destes, 5/7 mostraram que mutações estão associadas a pior sobrevida (Tabela 1). Os resultados mais expressivos foram observados no linfoma de células do manto $(40,41,42)$. Também no grupo de linfomas de grandes células $B$, tratados de forma homogênea e avaliados por Ichikawa et al., esta correlação pode ser estabelecida (43). No entanto, com relação ao linfoma de Burkitt, uma neoplasia linfóide com alta freqüência de mutações do gene p53, Preudhomme et al. (44) não observaram correlação entre mutações e pior sobrevida, embora, em estudo anterior, esta correlação tenha sido sugerida por outros autores (45). A dificuldade de análise em alguns estudos está relacionada ao uso de populações heterogêneas (46), diferentes métodos de análise e objetivos não definidos.

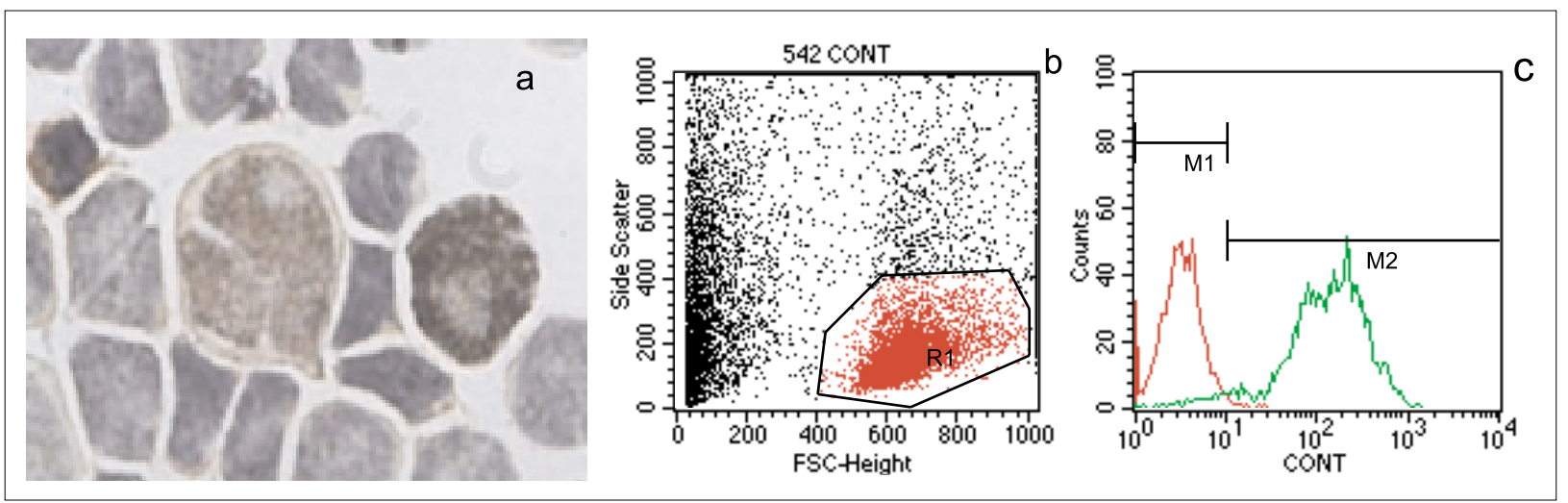

Figura 5. Expressão da proteína p53 em um caso de Leucemia linfóide crônica

a) Deteç̧ão nuclear da proteína por ICQ; Detecção por Citometria de fluxo : b) Dot plot para seleção de células linfóides; c) Histograma da marcação com AcMo anti-p53 (D0-7 DAKO) mostrando expressão em $97 \%$ das células neoplásicas

(Resultados dos autores) 
Tabela 1. Sumário dos resultados da pesquisa de mutações do gene p53 por PCR-SSCP e seqüenciamento em linfoma não Hodgkin

\begin{tabular}{|c|c|c|c|c|c|}
\hline Referência & $\begin{array}{c}N^{\circ} \\
\text { pacientes }\end{array}$ & $\begin{array}{c}\text { Tipo } \\
\text { Histológico }\end{array}$ & Estágio & Tratamento & $\begin{array}{c}\text { Análise } \\
\text { Multivariada }\end{array}$ \\
\hline Koduru et al. ${ }^{46}$ & 237 & $\begin{array}{l}\text { L. Células B } \\
\text { baixo e alto grau }\end{array}$ & $N R$ & $N R$ & $N R$ \\
\hline $\begin{array}{l}\text { Ichikawa } \\
\text { Et al. }\end{array}$ & 102 & $\begin{array}{l}\text { L. Difuso de } \\
\text { grandes células B }\end{array}$ & Todos & QT & $\mathrm{S}$ \\
\hline $\begin{array}{l}\text { Hernandez } \\
\text { Et al. }\end{array}$ & 43 & L. Células do manto & III e IV & QT & $\mathrm{S}$ \\
\hline Greiner et al. ${ }^{41}$ & 53 & L. Células do manto & $N R$ & $N R$ & $\mathrm{~S}$ \\
\hline Louie et al. ${ }^{42}$ & 23 & L. Células do manto & $N R$ & $\begin{array}{c}\mathrm{QT} \text { ou } \\
\mathrm{QT}+\mathrm{RT}\end{array}$ & $\mathrm{S}$ \\
\hline $\begin{array}{l}\text { Preudhomme } \\
\text { Et al. }{ }^{44}\end{array}$ & 48 & $\begin{array}{l}\text { L. Burkitt/ LLA- } \\
\text { L3 }\end{array}$ & Todos & QT & $\begin{array}{c}\text { NS } \\
\text { S }\end{array}$ \\
\hline $\begin{array}{l}\text { Gutierrez } \\
\text { Et al. }^{45}\end{array}$ & 21 & $\begin{array}{l}\text { L. Burkitt-like e L. } \\
\text { alto grau B }\end{array}$ & II e III & QT & $\mathrm{S}$ \\
\hline
\end{tabular}

NR: não referido; QT: quimioterapia; RT: radioterapia; S: significante; NS: não significante.

Em outras neoplasias linfóides, como a leucemia linfoblástica aguda, a freqüência de mutações descritas é baixa $(36,47,48)$. Um achado ainda difícil de ser interpretado é a detecção de alta freqüência de mutação (28\%) na Hairy cell leukemia, uma forma de leucemia de bom prognóstico, cuja terapêutica é menos agressiva (49).

De forma ideal, os futuros estudos devem envolver grande número de pacientes tratados com idênticos esquemas terapêuticos e estratificados em tipos histológicos, de forma a validar os resultados visando a pesquisa de rotina de mutações do gene p53 e seleção de pacientes com pior prognóstico para modalidades terapêuticas mais agressivas.

A maioria das investigações sobre 0 valor preditivo de alterações do gene $p 53$ tem examinado o acúmulo da proteína p53 utilizando $\mathrm{IH}$. As dificuldades de normatizar a metodologia da IH e interpretação dos resultados pode explicar as discrepâncias entre os diferentes estudos e o limite da aplicação clínica destes resultados (Tabela 2). Tem sido demonstrado que a p53 pode ser detectada por IH na ausência de mutação em diversas situações, como flutuação dos níveis da forma selvagem em resposta ao dano no DNA e, no caso de ligação a proteínas virais e outras proteínas $(10,50,51)$.

0 principal mecanismo de controle da atividade da p53 é o controle da estabilidade da proteína. Em células normais, a p53 está presente em baixos níveis porque é rapidamente degradada após a síntese. Um dos mais importantes componentes da via de degradação da p53 é o produto do gene $M d m 2$. A ação principal da proteína MDM2 é interagir diretamente com a p53 e inibir sua atividade (52).

Embora o controle da estabilidade da p53 seja um processo complexo, a detecção esporádica da p53 no timo e em linfadenite inespecífica sugere que a estabilização nestes casos pode ser dependente de ligação a outras proteínas (53). 
Tabela 2. Análise dos resultados da expressão da proteína p53 em neoplasias linfóides

\begin{tabular}{|c|c|c|c|c|c|}
\hline Referência & No & Classificação & Tratamento & $\begin{array}{r}I H / I C Q \\
(\%)\end{array}$ & $\begin{array}{l}\text { Análise } \\
\text { Estatística }\end{array}$ \\
\hline Kramer et al ${ }^{59}$ & 372 & $\begin{array}{l}\text { LNH difuso de } \\
\text { grandes células }\end{array}$ & QT & $17 \%^{a}$ & NS \\
\hline Sanchez et al ${ }^{60}$ & 141 & $\begin{array}{l}\text { LNH difuso de } \\
\text { grandes células }\end{array}$ & $\begin{array}{l}\text { QT, RT ou } \\
\text { QT/RT }\end{array}$ & $30 \%{ }^{b}$ & NS \\
\hline $\begin{array}{l}\text { Navaratnam } \\
\text { Et al. }\end{array}$ & 50 & $\begin{array}{l}\text { LNH difuso de } \\
\text { grandes células }\end{array}$ & QT & $40 \%{ }^{b}$ & $\mathrm{~S}$ \\
\hline Pires et al ${ }^{66}$ & 119 & $\begin{array}{l}\text { LNH difuso de } \\
\text { grandes células }\end{array}$ & $\begin{array}{l}\text { QT, RT } \\
\text { ou QT/RT }\end{array}$ & $26 \%^{d}$ & $\mathrm{~S}$ \\
\hline Moller et al ${ }^{67}$ & 199 & $\begin{array}{l}\text { LNH Baixo e } \\
\text { alto grau, B e T }\end{array}$ & $\begin{array}{l}\text { QT, RT } \\
\text { ou QT/RT }\end{array}$ & $21 \%^{c}$ & $\mathrm{~S}$ \\
\hline $\begin{array}{l}\text { Korkolopoulou } \\
\text { et al }\end{array}$ & 91 & $\begin{array}{l}\text { LNH Baixo e alto } \\
\text { grau, B e Tou }\end{array}$ & $\begin{array}{l}\mathrm{QT}, \mathrm{RT} \\
\mathrm{QT} / \mathrm{RT}\end{array}$ & $47 \%^{d}$ & $\mathrm{~S}$ \\
\hline Pagnano et al ${ }^{72}$ & 61 & $\begin{array}{l}\text { LNH difuso de } \\
\text { grandes células, } \\
\text { T periférico }\end{array}$ & QT & $30 \%^{a}$ & $\mathrm{~S}$ \\
\hline Adamson et al ${ }^{57}$ & 38 & $\begin{array}{l}\text { LNH Baixo e } \\
\text { alto grau }\end{array}$ & NA & $4 \%^{f}$ & NA \\
\hline $\begin{array}{l}\text { Hernandez } \\
\text { et al }\end{array}$ & 43 & Linfoma do manto & QT & $2 \%^{b}$ & $\mathrm{~S}$ \\
\hline Louie et al ${ }^{42}$ & 23 & Linfoma do manto & $\begin{array}{l}\text { QT ou } \\
\text { QT/RT }\end{array}$ & $22 \%^{b}$ & $\mathrm{~S}$ \\
\hline 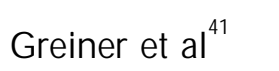 & 53 & Linfoma do manto & NA & $13 \%^{b}$ & $\mathrm{~S}$ \\
\hline Cordone et al ${ }^{31}$ & 181 & LLC & QT & $15 \%^{a} *$ & $\mathrm{~S}$ \\
\hline $\begin{array}{l}\text { Brito-Babapulle } \\
\text { et al }\end{array}$ & 24 & $\begin{array}{l}\text { Leucemia } \\
\text { prolinfocítica T } \\
\text { e Sindrome de Sèzary }\end{array}$ & NA & $63 \%^{\mathrm{e}} *$ & NA \\
\hline \multicolumn{6}{|c|}{$\begin{array}{l}\text { IH: Imunohistiquímica; *ICQ: Imunocitoquímica; Positivo: a) } \geq 1 \% \text { de células coradas; b) } \geq 5 \% \text {; } \\
\text { c) } \geq 20 \% \text { ou } \geq 5 \% \text { se simultâneamente p } 21 \text { neg.; d) qualquer marcação; e) } \geq 10 \% ; \text { f) }<5 \% \text {; } \\
\text { S: significante; NS: não significante; NA: não avaliado. }\end{array}$} \\
\hline
\end{tabular}


Diversos estudos tentaram utilizar a IH como método de screning de mutações da p53. No entanto, em tecidos linfóides, a reatividade observada em linfadenites sugeria que a estabilização da proteína ocorria por outros mecanismos independentes da mutação $(53,54)$. Posteriormente foi demonstrado, nos linfomas não Hodgkin (LNH), que a correlação da expressão era maior com mutações do tipo missense e que diferentes alterações da p53 podem ocorrer aumentando sua estabilidade (46, $55,56,57)$. Por outro lado, tem sido proposto que mutações do tipo nonsense podem levar à produção de uma proteína truncada impossível de ser detectada por IH (55).

A tabela 2 mostra as diferenças de metodologia de estudo da p53 e a interpretação em pacientes com expressão da proteína p53. Com relação à $\mathrm{IH}$, os estudos devem ser examinados com cautela. Como exemplo em um mesmo tipo histológico de LNH, a análise da sobrevida livre de eventos de Navaratnam et al. (58) mostra pior sobrevida para os pacientes com expressão da p53, enquanto que em três outros estudos esta associação não foi comprovada (59-61).

Na leucemia linfóide crônica, a expressão da p53 analisada por ICQ mostrou correlação significativa com a presença de mutações, estágio mais avançado, pior resposta ao tratamento e encurtamento da sobrevida (31) (Tabela 2). Alterações como deleção alélica do gene $p 53$, observadas com freqüência na leucemia prolinfocítica T (LPL-T) e Síndrome de Sézary, associaram-se ao acúmulo da proteína p53 na ausência de mutação (62). 0 mecanismo de estabilização da proteína nesses casos de LPL-T e síndrome de Sézary é desconhecido (Tabela 2).

As neoplasias linfóides são multifatoriais em sua patogênese e, embora tenham com freqüência um evento inicial (em geral uma translocação), outros eventos ocorrem neste processo. Tentando compreender melhor este processo, fatores biológicos relacionados à funções da célula como proliferação, progressão no ciclo celular e apoptose, vêm sendo pesquisados. Dentro deste contexto, alguns estudos de investigação da expressão de proteínas tais como p21, MDM2, c-myc, Bcl-2, p16 e p27 em associação à expressão da p53 foram realizados $(59,60,63,67)$.

A mutação do gene $p 53$ tem como resultado a falha de indução da expressão do gene $\mathrm{p} 21^{\text {Waf1 }}$, cuja proteína age como um bloqueador do ciclo celular induzindo à parada da célula em G 1 para o reparo do DNA ou apoptose. Molller et al. demonstraram que a expressão da p53 associada à ausência da p21 tem 100\% de especificidade e sensibilidade como preditiva de mutação nos LNH de grandes células (67) (Tabela 2). Este achado também havia sido observado anteriormente por outros autores (68). Villuendras et al. observaram que os casos de LNH com mutação do gene p53 apresentavam ausência ou baixa expressão da p21 e MDM2, sugerindo que mutações do gene p53 estão relacionadas a incapacidade de transativar a p21 ${ }^{\text {Waf1 }}$ e MDM2. A associação entre mutações do tipo missense e o fenótipo $\mathrm{p} 53^{+}$, MDM2， p21; teve significado estatístico ( $p=$ 0.0024) neste estudo (69).

Em outra abordagem, em uma série de LNHs, - acúmulo da proteína p53 na ausência de mutação dos genes $p 53$ e $p 21$ estava associado à expressão da p21, indicando que nestes linfomas, a p53 é funcionalmente ativa sendo capaz de transativar 0 gene $p 21$.

A expressão anormal da p53 nesses linfomas sugere que outros mecanismos relacionados à proteínas envolvidas no ciclo celular possam estar alterados independente da integridade da via p53 (70).

A co-expressão de p53 e c-myc, uma proteína chave no controle da proliferação celular, foi analisada em 21 casos de LNH de grandes células e mostrou correlação com curso clínico mais agressivo e menor sobrevida (71). Entretanto, o número de casos é pequeno para uma conclusão definitiva dessa associação. Em estudo recente, Pagnano et al. observaram que a expressão de p53, c-myc e MDM2 estava relacionada à sobrevida mais curta em pacientes com LNH agressivo. Esta observação sugere que estes marcadores, associados a fatores de prognóstico já descritos, podem ser úteis na estratificação de risco visando intervenções terapêuticas mais efetivas (72). 


\section{Conclusões e D ireções Futuras}

O número de estudos referidos mostra que a pesquisa de alterações do gene e da proteína p53 em neoplasias, em especial as de origem linfóide, são relevantes para a compreensão da patogênese, evolução e resistência ao tratamento nessas neoplasias.

Até o momento os resultados da pesquisa dessas alterações são heterogêneos e só permitem uma conclusão definitiva em alguns tipos histológicos de LNH. De forma ideal, os futuros estudos devem envolver grande número de pacientes tratados com idênticos esquemas terapêuticos e estratificados em tipos histológicos, de forma a validar os resultados visando a pesquisa de rotina de mutações do gene p53 e seleção de pacientes para modalidades terapêuticas mais agressivas.

Um grande progresso foi alcançado nos últimos anos no entendimento das funções da p53 e sua regulação. Estes esforços hoje se traduzem no desenvolvimento de estratégias terapêuticas como a terapia gênica utilizando a forma selvagem e o desenvolvimento de agentes farmacológicos com ação independente da p53 ou, que agem preferencialmente em células com a forma alterada da proteína. Tentativas vêm sendo desenvolvidas usando inativação anti-senso da MDM-2. Esta estratégia poderá ser utilizada em células que têm a forma selvagem da p53 inativada por mecanismos independentes de mutação (73). Uma abordagem de indução seletiva da apoptose em células com o gene mutado através do adenovírus humano foi recentemente empregada (74). Como em muitos outros campos, o sucesso destas estratégias está relacionado ao aumento do conhecimento das funções biológicas da p53 e o uso criativo de tal conhecimento.

\section{Evaluation of detection methods of alterations of the P53 gene and protein in lymphoid neoplasms}

Claudete E. Klumb, Geraldo B. Cavalcanti Júnior

\section{Abstract}

The p53 protein plays a central role in cellular responses, including cycle arrest and cell death in response to DNA damage. Dysfunction of this protein can induce abnormal cell growth, increased cell survival, and drug resistance. The p53 tumor suppressor gene is altered in many types of human cancer including hematological malignancies. Most of the p53 biologically significant mutations impair the ability of protein to act as a transcriptional regulator. Unlike functional p53, which is rapidly degraded after its synthesis, mutated forms tend to accumulate in the cells, thus becoming detectable by immunohistochemistry. Its has been reported that mutations of p53 gene occur with a frequency of approximately $12.5 \%$ in lymphoid malignancies. However, aggressive non-Hodgkin's lymphomas (NHL), especially Burkitt's lymphoma, show higher frequencies. Most p53 gene mutations in NHL are missense mutations, stabilising the functionally defective protein, but wild-type form of p53 protein also has a high p53 expression detected by immunohistochemistry indicating a discrepancy between gene mutation and protein detection.

The aim of this work is to perform a comprehensive review of the methods used to identify gene alterations and p53 protein expression in lymphoid neoplasias in order to investigate its involvement in these neoplasias. Rev.bras. hematol.hemoter.,2002, 24(2): 111-125

Keywords: p53 tumor suppressor gene, p53 protein, lymphoid neoplasias

\section{Referências Bibliográficas}

1. Harris CC. p53 tumor supressor gene: from basic research laboratory to the clinic: an abridged historical perspective C arcinogenesis 1996; 17: 1187-1198.

2. Wang XW, Harris CC. p53 tumor-supressor gene: Clues to molecular carcinogenesí. J C ell Physiol 1997; 173: 247-255. 
3. Levine AJ. p53, the cellular gatekeeper for grow th and division. C ell 1997; 88: 323-331.

4. Bates S, Vousden KH. Mechanisms of p53mediated apoptosis. C ell M ol Life Sci 1999; 55: 28-37.

5. Hernandez-Boussard T, Rodriguez-Thome $P$, Montesano R, Hainaut P. IARC p53 mutation database to compile and analyse p53 mutations in human tumors and cell lines.

H um M utat 1999; 1-8.

6. Bartek J, Bartkova J, Vojtesek B, et al. Aberrant expression of p53 oncoprotein is a common feature of wide spectrum of human malignancie s. O ncogene 1991; 6: 1699-1703.

7. Lane DP. Cancer: p53, guardian of the genome. N ature 1992; 558:15-16.

8. Blandino G, Levine AJ, Oren M. Mutant p53 gain of function: differential effects of different p53 mutants on resistance of cultured cells to chemotherapy. O ncogene 1999; 18:477-485.

9. Hainaut P, Hollstein M. p53 and cancer: the first ten thousand mutation s. Adv Cancer Res 2000; 77:82-137.

10. Lane DP, Crawford LV. T-antigen is bound to host protein in SV40 transformed cells N ature 1979; 278: 261-263.

11. Hainaut $P$. Le gène suppresseur de tumeurs TP53: vingh ans (et dix mille mutations) aprés. Bull C ancer 2000; 87:11-8.

12. O ren $\mathrm{M}$, Rotter $\mathrm{V}$. Introduction: $p 53$, the first twenty years. Cell M ol Life Sci 199

13. Steele RJC, Thompson AM, Hall PA, Lane DP. The $p 53$ tumour suppressor gere. $\mathbf{B r} \mathbf{J}$ Surg 1998; 85: 1460-1467.

14. Matlashewski G. p53: Twenty years on, Metting Rewiew. O ncogene 1999; 18: 76187620.

15. Orita $M$, I wahana $H$, Kanazawa $H$, et al. Detection of polymrphisms of human DNA by gel electrophoresis as single-strand conformation polymorphism. Proc $\mathbf{N}$ atl Acad Sci USA 1989; 86: 2766-70.

16. Murakami Y, Hayashi K, Skiya T. Detection of aberrations of p53 alleles and the gene transcript in a human tumor cells lines by single-strand conformation polymorphism analysi s. C ancer Res 1991; 51: 3356-61.
17. Hayashi K. PCR-SSCP: a simple and sensitive method for detection in genomic DNA.PC R Methods and Appl 1991; 1:34-8.

18. Sambrook J and Russel DW. Detection of mutations by single-strand conformational polymorphism and heteroduplex analysis In: Sambrook J and Russel DW (ed): Molecular Cloning: a laboratory manual, 3nd edition. New York: Cold Spring H abor 2001:13.49.

19. Rohlfs EM and Jr Highsmith WE. PCR-based methods for mutation detection. In: Coleman WB and Tsongalis GJ (ed): Molecular diagnosis for the clinical laboratorian, 1nd edition. New Jersey: H uman Press 1997: 123-157.

20. Logullo AF, Pereira de Moura R, Nonogaki S, Kowalski LP, Nagai MA and Simpson AJG. $A$ proposal for the integration of immunohistochemical staining and DNABased techniques for the determination of TP53 mutations in human carcinomas.

D iagn M ol Pathol 2000; 91: 35-40.

21. Sanger F, Nicklen S, Coulson AR. DNA sequencing with chain-terminating inhibitors. Proc Natl Acad Sci USA 1977; 74: 5463-5467.

22. Griffths AJF, Miller JH, Suzuki DT, Lew ontin RC, Gelbart WM (ed). An introduction to genetics analysis, 6nd edition. New York: W H Freeman and Company 1996: 444-448.

23. Mc Bride OW, Merry D, Givol D. The gene for human p53 cellular tumor antigen is located on cromosome 17 short arm (17p13). Proc N atl Acad Sci U SA, 1996; 83: $130-134$.

24. Cowlen MS. Nucleic acid hybridization and amplification in situ. In: Coleman WB and Tsongalis GJ (ed): Molecular diagnosis for the clinical laboratorian, 1nd edition. New Jersey: H umana Press 1997: 163-191.

25. Martin A. Le gène supresseur de tumeur $p 53$ ( $2^{e}$ partie). Aplications em pathologie humain e. Ann Pathol 1995. 15: 184-191.

26. Iggo R, Gatter K, Bätek J et al. Increased expression of mutant forms of p53 oncogene in primary lung cance $r$. Lancet 1990; 335: 675- 679. 
27. Yandell DW, Thor AD. p53 analysis in diagnostic pathology. Biologic implications and possible clinical applications. D iagn M ol Pathol 1993; 2:1-3.

28. Wynford-Thomas D. p53 in tumour pathology: can we trust immunohistochemistry? J Pathol 1992; 166: 329-330.

29. Hall PA, Lane DP. p53 in tumour pathology: can we trust immunohistochemistry? Revisited!J Pathol 1994; 172: 1-4.

30. Dowell SP, Wilson POG, Derias NW et al. Clinical utiliy of the immunocytochemistry detection of $p 53$ protein in cytological specimens. C ancer Res 1994; 54: 2914-2918.

31. Cordone I, Mais S, Mauro FR et al. p53 expression in $B$ lymphocytic leukemia: $A$ marker of disease progression and poor prognosis. Blood 1998; 11: 4342-4349.

32. Danova M, Giodano M, Mazzini G, Riccardi A. Expression of p53 protein during the cell cycle measured by flow cytometry in human Leukemia. Leuk Res 1990; 14: 417-422.

33. Fillippini G, Griffin S, Uhr M et al. A novel flow cytometry method for the quantification of p53 gene expressia. Cytometry 1998; 31: 180-186.

34. Faharat $N$, van der DP, Praxedes $M$ et al. Demonstration of cytoplasmic and nuclear antigens in acute leukaemia using flow cytometry. J C lin Phatol 1994; 47: 843-849.

35. Bhatia K, Goldschmidts W, Gutierrez M et al. Hemi or homozygosity: a requirement for some but not other $p 53$ mutant accumulate and exert a pathogenetic effect. FASE B J 1993; 7: 951-956.

36. Imamura J, Miyoshi I, Koeffler PH. p53 in hematologic malignancies. Blood 1994; 84: 2412-2421.

37. Sugito S, Yamato K, Sameshima $Y$ et al. Adult T-cell leukemia: Structures and expression of p53 gere. Int J C ancer 1991; 49: 880- 885.

38. Gaidano G, Ballerini P, Gong JZ et al. p53 mutations in human lymphoid malignancies: Association with Burkitt lymphoma and chronic lymphocytic leukemia. Proc N atl Acad Sci USA 1991; 88: 5413-5417.
39. Nieder C, Petersen S, Petersen C, Thames HD. The chalenge of $p 53$ as prognostic and predictive factor in Hodgkin's or non-Hodgkin's lymphoma. Ann Hematol 2001; 80:2-8.

40. Hernandez L, Fest $T$, Cazola $M$ et al. p53 gene mutations and protein overexpression are associated with agressive variants of mantle cell lymphomas. Blood 1996; 87: 3351-3359.

41. Greiner TC, Moynihan MJ, Chan WC et al. p53 mutations in mantle cell lymphoma are associated with variant cytology and predict a poor prognosis. Blood 1996; 87: 4302-4310.

42. Louie DC, Offit K, Jaslow R et al. p53 overexpression as a matter of poor prognosis in mantle cell lymphomas with $t(11 ; 14)$ (q13;q32). Blood 1995; 86: 2892-2899.

43. Ichikawa A, Kinoshita $T$, Watanabe $T$ et al. Mutations of the $p 53$ gene as prognostic factor in agressive $B$-cell lymphom. N Engl J Med 1997; 337: 529-534.

44. Preudhomme C, Dervite I, Wattel E et al. Clinical significance of p53 mutations in newly diagnosed Burkitt's lymphoma and acute lymphoblastic leukemia: a report of 48 cases. J C lin 0 ncol 1995; 13: 812-820.

45. Gutierrez MI, Bhatia K, Diez B et al. Prognostic significance of $p 53$ mutations in small non-cleaved cell lymphomas. Int J O ncol 1994; 4:567-571.

46. Koduru PR, Raju K, Vadmal V et al. Correlation between mutation in p53, p53 expression, cytogenetics, histologic type, and survival in patients with $B$-cell nonHodgkin's lymphoma. Blood 1997; 90: 40784091.

47. Wada M, Bartram CR, Nakamura $\mathrm{H}$ et al. Analysis of $p 53$ mutations in a large series of lymphoid hematologic malignancies of childhood. Blood 1993; 82: 3163-3169.

48. Fenaux $\mathrm{P}$, Jonveaux $\mathrm{P}, \mathrm{Q}$ uiquandon et al. Leukemia 1992; 6: 42-46.

49. König EA, Kusser WC, Day $C$ et al. P53 mutation in hairy cell leukemia. Leukemia 2000; 14:706-711.

50. Werness BA, Levine AJ, Howley PM. Association of human papilloma virus types 16 and 18 E6 proteins with p53. 
51. Momand J, Zambettti GP, OIson DC et al. The mdm-2 oncogene product forms a complex with the p53 protein and inhibits p53-mediated transactivation . C ell 1993; 69: 1237-1245.

52. Ashcrof M, Vousden KH. Regulation of $p 53$ stability. O ncogene 1999; 18: 7637-7643.

53. Villuendas R, Pires MA, O rradre JL et al. P53 protein expression in lymphomas and reactive lymphoid tissue. J Pathol 1992; 166: 235-241.

54. Villuendas R, Pires MA, Algara $P$ et al. The expression of p53 protein in nonHodgkin's lymphoma is not always dependent on p53 gene mutations. Blood 1993; 82: 3571-3556.

55. Martinez-Delgado B, Robledo M, Arranz E et al. Correlation between mutations in p53 gene and protein expression in human lymphomas. Am J H ematol 1997; 55:1-8.

56. Kocialkowski S, Pezzela F, Morrison $\mathrm{H}$ et al. Mutations in the p53 gene are not limited to classic hot spots and not predictive of $p 53$ protein expression in high-grade nonHodgkin's lymphoma. Br J H ematol 1995; 89: 55-60.

57. Adamson DJA, Thompson WD, Dawson AA et al. p53 mutattion and expression in lymphoma. Br J C ancer 1995; 72: 150-154.

58. Navaratnam $S$, Williams $G$ J, Rubinger $M$ et al. Expression of p53 predicts treatment failure in aggressive non-Hodgkin's lymphomas. Leuk Lymphoma 1998; 29: 139-144.

59. Kramer $\mathrm{MH}$, Hermans J, Parker J et al. Clinical significance of $\mathrm{bcl}-2$ and $\mathrm{p} 53$ protein expression in diffuse large $B$-cell lymphoma: a population based study. J C lin O ncol 1996; 14: 2131-2138.

60. Sanchez E, Chacon I, Plaza MM et al. Clinical outcome in diffuse large B-cell lymphoma is dependent on the relationship between diferent cell-cycle regulator proteins. J C lin Oncol 1998; 16:1931-1939.

61. Maia RC, Mendes GQ, Magalhães LM et al. Immunohistochemical analysis of p53 and bcl-2 expression in high-grade non-Hodgkin lymphomas: correlation with clinical outcome. In: 17th International Cancer Congress, Rio de Janeiro, 1998:1375-1378.

62. Brito-Babapulle V, Hamoudi R, Matutes E et al. p53 allele deletion and protein accumulation occurs in the absence of p53 gene mutation in $T$-prolymphocytic leukaemia and Sezary syndrome. Br J H aematol 2000; 110: 180-187.

63. Wyndham HW, Teruya-Felstein, Fest T et al. Relationship of $\mathrm{p53}, \mathrm{bcl}-2$, and tumor proliferation to clinical drug resistence in non-Hodgkin's lymphomas. Blood 1997; 89: 601-609.

64. Sánchez-Beato M, Sáez AI, Navas IC et al. Overall survival in agressive $B$-cell lynphomas is dependent on accumulation of $p 53$ alterations in p53, p16, and p27. Am J Pathol 2001; 159: 205-213.

65. Korkolopoulou P, Angelopoulu MK, Kontopidou et al. Prognostic relevance of apoptotic cell death in non-Hodgkin's lymphomas: a multivariate survival analysis including Ki67 and p5 3. H istopathology 1998; 33: 240-247.

66. Pires MA, Pezzella F, Martinez-Montero et al. p53 and bcl-2 expression in high $B$-cell lymphomas: correlation with survival time.

Br J C ancer 1994; 69: 337-341.

67. Moller BM, Gerdes AM, Skjodt K et al. Disrupted $p 53$ function as predictor of treatment failure and poor prognosis in $B$ cell non-Hodgkin's lymphoma. Clin C ancer Res 1999; 5: 1085-1091.

68. Chilosi M, Doglioni C, Magalini A et al. p21/ WAF1 cyclin-kinase expression in nonHodgkin's lymphomas: a potential marker of p53 tumor-suppressor gene function.Blood 1996; 88: 4012-4020.

69. Villuendas R, Pezzella F, Gatter K et al. p21 $1^{\text {WAF1/CIP1 }}$ and MDM2 expression in nonHodgkin's lymphoma and their relationship to $p 53$ status: A p53+, MDM2 - , p21-immunophenotype associated with missense p53 mutations. J Pathol 1997; 181: 51-61.

70. Maestro R, Gloghini A, Doglioni $C$ et al. Human non-Hodgkin's lymphomas overexpress a wild-type form of $p 53$ which is 
a functional transcriptional activator of cyclin-dependent kinase inhibitor p21. Blood 1997; 89: 2523-2528.

71. Chang CC, Liu YC, Cleveland RP et al. Expression of c-myc and p53 correlates with clinical outcome in diffuse large $B$-cell lymphomas. Am J Clin Pathol 2000; 113; 512-518.

72. Pagnano KBB, Vassalo J, Lorand-Metze I et al. p53, Mdm2, and c-myc overexpression is associated with a poor prognosis in agressive non-Hodgkin's lymphomas. Am J H ematol 2001; 67:84-92.

73. Gallagher WM, Brown R. p53-Oriented cancer therapies: Current progress. Ann O ncol 1999; 139-150.

74. Beard P. Virus mediated killing of cells that lack p53 activity. N ature 2001; 412: 914-917.

\section{Agradecimentos}

As ilustrações deste trabalho foram resultado dos estudos realizados no Laboratório de Hematologia Celular e Molecular / Serviço de Hematologia do Hospital do Câncer e Laboratório de Bioquímica e Biologia Molecular do Departamento de Bioquímica Médica da Universidade Federal do Rio de Janeiro. Agradecemos a Dra Raquel C. Maia pela revisão do texto e análise crítica deste estudo e ao Professor Franklin David Rumjanek pela orientação nos experimentos na área de biologia molecular.

Recebido - 04/02/2002

Aceito - 28/04/2002 